\title{
Evaluation of using radiographic films in measurements of penumbra width for radiotherapy applications
}

\author{
Ehab A. Hegazy \\ Department of basic science, Faculty of pharmacy, Delta University for science and technology, Mansoura, \\ Egypt \\ Ehabhegazy99@yahoo.com
}

\section{ABSTRACT}

The accuracy of treatment field size in is a success key in cancer radiotherapy. As Increase in dose may lead to overdose side effects, and decrease in dose lead to subtherapeutic effect which increased incidence of tumor recurrence or incomplete recovery of patient. Many physical parameters should be measured very accurately in order to predict the dose distribution as physical penumbra of radiation fields. Ionization chamber is considered as slandered tools for measuring penumbra.

Mega voltage $\mathrm{x}$-ray energy penumbra is measured using ionization chamber due to its high accuracy in measuring absolute dose. This technique can produce the gold standard for penumbra measurements; however, it is a very time consuming and demanding process.

Aim of this work is to evaluate the using radiographic films in penumbra width measurements for radiotherapy applications and stereotactic radiosurgery by comparing results obtained by standard ionization chambers to radiographic films as new tool for penumbral width measurements.

Comparison between penumbra region measured by ionization chamber and $0-x m a t ~ v$ Kodak radiographic films were carried out under the same physical and dosimeteric conditions.

Penumbra width differences were found to be less than $1 \mathrm{~mm}$ for $6 \mathrm{mev}, 15 \mathrm{mev}$ photon beam and $6 \mathrm{mv}$, $15 \mathrm{mv}$ electron beam used in radiotherapy. Measured differences were considered very small and has no effect on penumbra width measurements however o-xmat $v$ Kodak films provide fast .easy and economic method for penumbra measurement used in radiotherapy dosimetery.

\section{Indexing terms/Keywords}

Radiotherapy, ionization chamber, penumbra, photon, electron, radiographic film

\section{SUBJECT CLASSIFICATION}

Experimental Medical Physics

\section{INTRODUCTION}

In recent years, the spectacular technological advances in radiotherapy have generated much enthusiasm ${ }^{[1]}$.

Quality assurance (QA) has long been an integral part of the field of radiation oncology, although interest has increased sharply in recent years due to the great impotance of safety challenges presented by novel technologies and automated radiotherapy new high techniques ${ }^{[2,3]}$.

Intensity modulated radiation therapy (IMRT) has become the first choinse of treatment technique for many types of cancers such as prostate, head and neck, and breast ${ }^{[4-8]}$.

The gradual decrease of dose is called penumbra ${ }^{[9]}$.Penumbra is the region near the edge of the field margin where the dose falls rapidly ${ }^{[10]}$. The dose falls off around the geometric beam edge that is sigmoid in shape and lasts under the linear accelerator independent jaws ${ }^{[11]}$, also penetration of beams trough collimator may contribute to form penumbra where there is also scattering of radiation which has a great role in radiotherapy. The total penumbra is referred to the physical penumbra and it is the sum of the three individual penumbras ${ }^{[12,13]}$.

Mega voltage x-ray energy penumbra is measured using ionization chamber due to its high accuracy in measuring absolute dose. This technique can produce the gold standard for penumbra measurements; however, it is a very time consuming and demanding process ${ }^{[14,15]}$. Aim of this work is to evaluate the using radiographic films in penumbra width measurements for radiotherapy applications and stereotactic radiosurgery by comparing results obtained by standard ionization chambers to radiographic films as new tool for penumbral width measurements.

\section{Materials and Method}

lonization chamber (PTW $0.6 \mathrm{~cm}^{3}$ ) is used in this study was calibrated by General National Laboratory, Braunschweig, Germany. Therapy Beam Analyzer (MP3-S) system consists of a Perspex tank a moving mechanism, TBA control unit, control pendant, Tandem dual channel electrometer, Semiflex ionization chamber $\left(0.125 \mathrm{c}^{3}\right)$, and MEPHYSTO (Medical Physics Tool) software. This software system is used for measurements of relative dose distributions by means of PTW water phantoms and PTW densitometers. MEPHYSTO allows data to be analyzed in compliance with internationally recognized protocols. Fibs Plus laser densitometer which is a computer controlled digital densitometer (FIPS PLUS laser scanner, PTW GmbH, Freiburg, Germany. The transmitted laser intensity is always digitized with a resolution of 12 bit to 
ensure optimum accuracy of the measuring values. The maximum spatial resolution of the FIPS PLUS Scanner can vary between $0.2 \mathrm{~mm}$ and $0.34 \mathrm{~mm}$. The Elekta multileaf collimator consists of 80 independent leaves which are divided into two banks. The material of the leaves is tungsten alloy with a density of $18.0 \mathrm{~g} / \mathrm{cm}^{3}$. The Elekta multileaf collimator has curved leaf ends and a stepped design for the leaf sides. Results obtained by using by ionization chamber were compared to Kodak X-omat V.

This study was carried out Mansoura university hospital, faculty of medicine ,department of oncology and nuclear medicine. Egypt.

\section{3- Results and Discussion}

\section{1 ionization chambers stability}

\begin{tabular}{llll}
\hline 6 MV & nC & Temp. C & kpa \\
\hline 300V & 30.42 & 20.1 & 102 \\
& 30.41 & 20.2 & 102 \\
\hline \multirow{2}{*}{ 200 V } & 30.42 & 20.2 & 102 \\
& 30.4 & 20.2 & 102 \\
\hline \multirow{2}{*}{ 100V } & 30.4 & 20.2 & 102 \\
& 30.39 & 20.3 & 102 \\
& 30.38 & 20.3 & 102 \\
\hline \multirow{2}{*}{ avg } & 30.38 & 20.3 & 102 \\
\hline
\end{tabular}

Table 1 Stability measurements of ionization chamber over changes of voltage for 6 Mv photon.

\begin{tabular}{|c|c|c|c|}
\hline $15 \mathrm{MV}$ & $\begin{array}{c}\text { Current } \\
\text { nC }\end{array}$ & $\begin{array}{c}\text { Temperature } \\
\text { Celsius }\end{array}$ & $\begin{array}{c}\text { Pressure } \\
\text { kpa }\end{array}$ \\
\hline \multirow[t]{3}{*}{$300 \mathrm{~V}$} & 35 & 20 & 102 \\
\hline & 35.1 & 20 & 102 \\
\hline & 35 & 20.2 & 102 \\
\hline \multirow[t]{3}{*}{$200 \mathrm{~V}$} & 34.9 & 20.2 & 102 \\
\hline & 34.99 & 20.2 & 102 \\
\hline & 34.9 & 20.1 & 102 \\
\hline \multirow[t]{4}{*}{$100 \mathrm{~V}$} & 34.98 & 20 & 102 \\
\hline & 34.98 & 20 & 102 \\
\hline & 34.98 & 20.2 & 102 \\
\hline & 34.89 & 20.1 & 102 \\
\hline
\end{tabular}

Table 2 stability Measurements of ionization chamber over changes of voltage for 15 Mev photon.

Tables 1 and 2 show relation between absolute dose reading of ionization chamber and operating voltage for different setups operating voltage $(100,200$ and 300$) v$ for $6 \mathrm{mv}$ and $15 \mathrm{mv}$ respectively. Difference in reading was within \pm 1 nanocoulombs which indicate high stability of ionization chamber.

\subsection{Characteristic curve}

The relation between optical density and dose is presented in figure 1 for $6 \mathrm{Mv}$ radiation beam by irradiating therapy verification film type Kodak X-Omat V. The film is exposed to different doses ranging from 1 cGy to 148 cGy at $1.5 \mathrm{~cm}$ depth using field size $20 \times 20 \mathrm{~cm}^{2}$ at $S S D=100 \mathrm{~cm}$. 


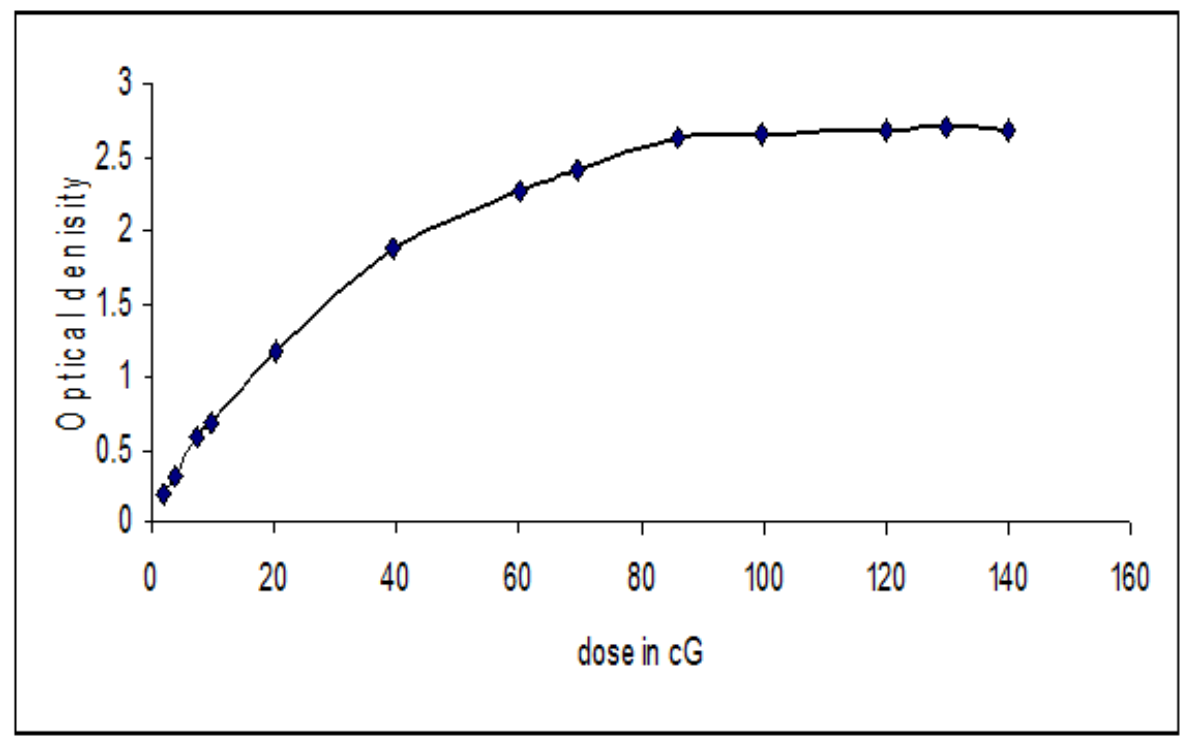

Figure 1 optical density versus the absorbed dose for radiographic films.

It is illustrated from figure 1 that between $0 \mathrm{cGy}$ to $80 \mathrm{cGy}$ the dose is proportional to the optical density, beyond this limit the optical density does not depend on the radiation dose. The film does not respond to the radiation doses. This limits our study at this dose.

\subsection{Penumbra measurements.}

\begin{tabular}{ccc}
\hline $\begin{array}{c}\text { Field Side } \\
\mathbf{c m}\end{array}$ & $\begin{array}{c}\text { Radiographic film } \\
\mathbf{m m}\end{array}$ & $\begin{array}{c}\text { Ionization } \\
\text { chamber } \mathbf{~ m m}\end{array}$ \\
\hline $\mathbf{5}$ & 3.2 & 2.9 \\
$\mathbf{7}$ & 3.3 & 3 \\
\hline $\mathbf{9}$ & 3.5 & 3.2 \\
$\mathbf{1 0}$ & 3.6 & 3.3 \\
$\mathbf{1 2}$ & 3.7 & 3.4 \\
$\mathbf{1 4}$ & 3.8 & 3.5 \\
$\mathbf{1 6}$ & 4 & 3.6 \\
\hline $\mathbf{1 8}$ & 4.1 & 3.7 \\
\hline $\mathbf{2 0}$ & 4.2 & 3.8 \\
\hline $\mathbf{2 2}$ & 4.2 & 3.8 \\
$\mathbf{2 4}$ & 4.3 & 3.9 \\
$\mathbf{2 6}$ & 4.4 & 4 \\
\hline $\mathbf{2 8}$ & 4.5 & 4.1 \\
\hline $\mathbf{3 0}$ & 4.6 & 4.2 \\
\hline
\end{tabular}

Table 3 Relation between field size and penumbra width at $D_{\text {max }}$ for different field sizes for 6 Mv photon. 


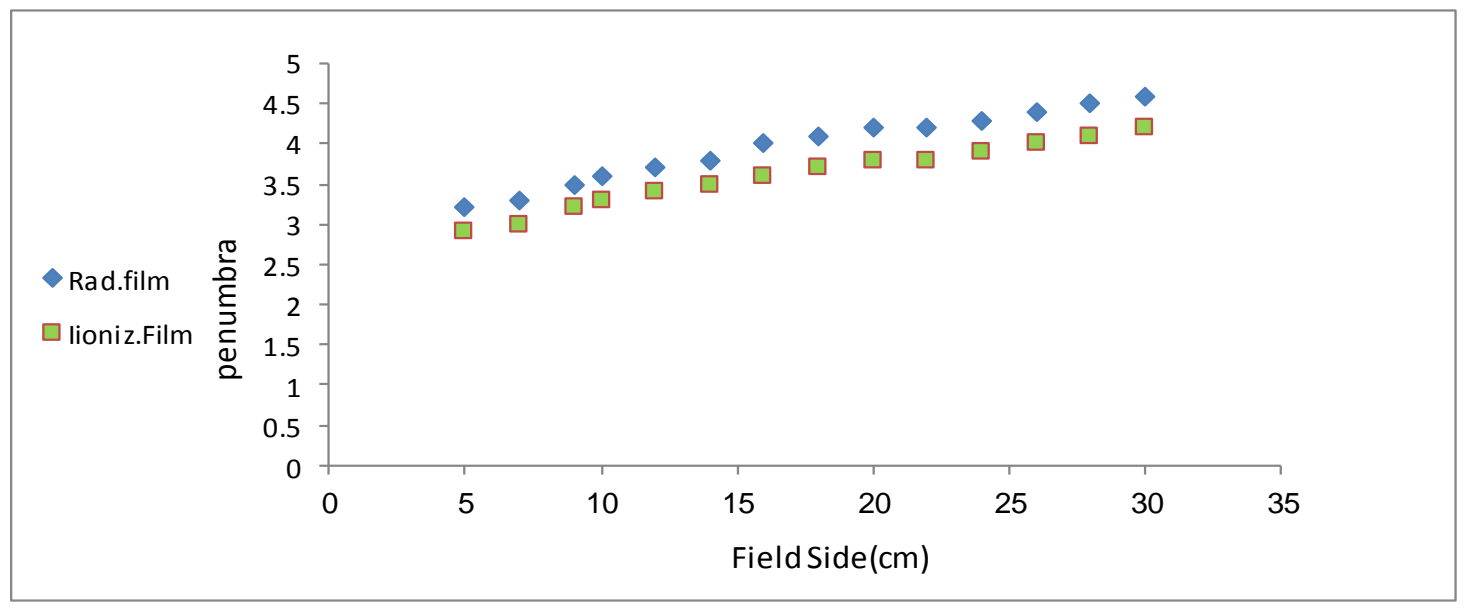

Figure 2 Relation between penumbra width and field size for photon beam and $6 \mathrm{mv}$ energy

The penumbra region measurements for $6 \mathrm{mv}$ photon beam by radiographic film and ionization chamber are presented in table 3 and Figure 2. Radiographic films show small increases in penumbra width around $(0.3 \mathrm{~mm})$ which can be attributed to the large energy dependence of the films response to $x$-rays. Penumbras are measured for different field size ranging from $10 \times 10 \mathrm{~cm}^{2}$ to $30 \times 30 \mathrm{~cm}^{2}$. Penumbra increase as field sizes increase for both ionization chamber and radiographic films.

\begin{tabular}{|c|c|c|}
\hline Field size $(\mathrm{mm})$ & $\begin{array}{l}\text { Radiographic film } \\
(\mathrm{mm})\end{array}$ & $\begin{array}{l}\text { Ionization chamber } \\
(\mathrm{mm})\end{array}$ \\
\hline 10 & 3 & 2.6 \\
\hline 12 & 3.1 & 2.7 \\
\hline 15 & 3.2 & 2.8 \\
\hline 18 & 3.25 & 2.85 \\
\hline 20 & 3.3 & 2.9 \\
\hline 22 & 3.3 & 2.9 \\
\hline 25 & 3.4 & 3 \\
\hline 27 & 3.5 & 3.1 \\
\hline 30 & 3.6 & 3.2 \\
\hline
\end{tabular}

Table 4 Relations between penumbra width and field size for $15 \mathrm{Mev}$ photon beam.

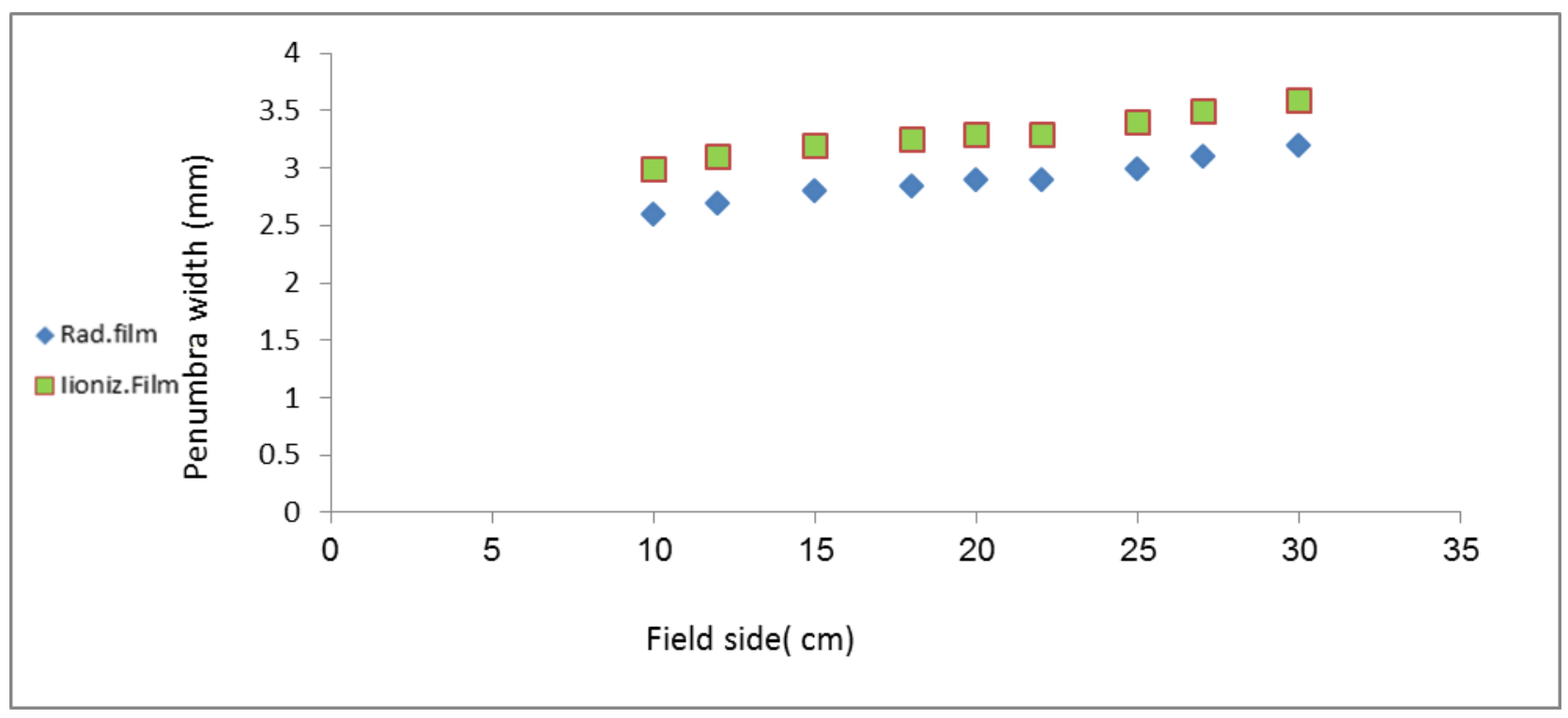

Figure 3 Relations between penumbra width and field size for 15 mev photon beam. 
The penumbra region measurements for $15 \mathrm{mv}$ photon beam by radiographic film and ionization chamber are presented in table 4 and Figure 3. Radiographic films show small increases in penumbra width around $(0.4 \mathrm{~mm})$ which can be attributed to the large energy dependence of the films response to x-rays. Penumbras are measured for different field size ranging from $10 \times 10 \mathrm{~cm}^{2}$ to $30 \times 30 \mathrm{~cm}^{2}$. Penumbra increase as field sizes increase for both ionization chamber and radiographic films.

\begin{tabular}{|c|c|c|}
\hline Field size $\left(\mathrm{cm}^{2}\right)$ & Radiographic films(mm) & $\begin{array}{l}\text { lonization chamber } \\
(\mathrm{mm})\end{array}$ \\
\hline $10 \times 10$ & 3.9 & 3.6 \\
\hline $12 \times 12$ & 4.2 & 3.9 \\
\hline $15 \times 15$ & 4.6 & 4.3 \\
\hline $18 \times 18$ & 4.8 & 4.5 \\
\hline $20 \times 20$ & 4.9 & 4.6 \\
\hline $22 \times 22$ & 5 & 4.7 \\
\hline $25 \times 25$ & 5.1 & 4.8 \\
\hline $27 \times 27$ & 5.2 & 4.9 \\
\hline $30 \times 30$ & 5.3 & 5 \\
\hline
\end{tabular}

Table 5 relation between penumbra width and field size for 6 mev electron beam.

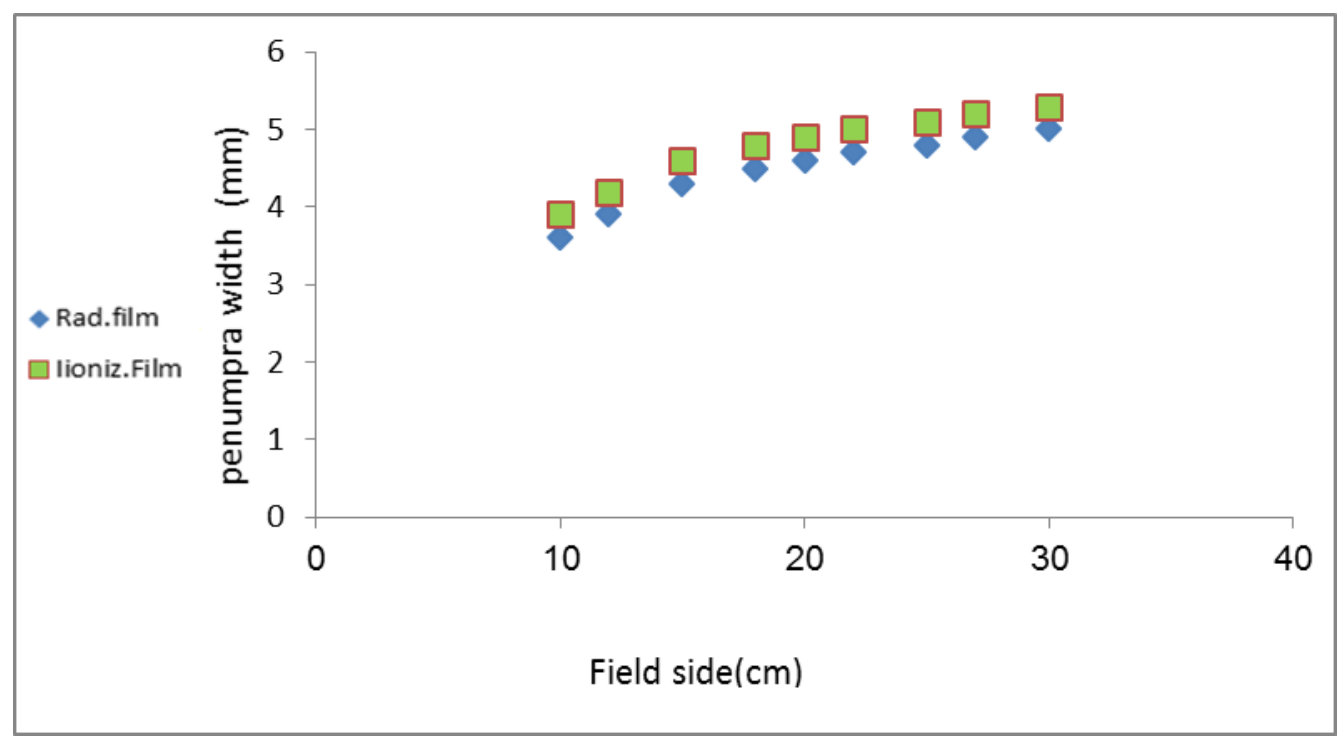

Figure 4 Relation between penumbra width and field size for electron beam and $6 \mathrm{mv}$ energy.

Comparison between penumbra region measured by radiographic film and ionization chambers is presented in table 5 and figure 4; we noticed that penumbra increase with increasing square field size and the penumbras measured by films larger than that measured by ionization chamber by about $0.3 \mathrm{~mm}$. 


\begin{tabular}{lcc}
\hline $\begin{array}{l}\text { Field size } \\
\text { cm } \times \text { cm }\end{array}$ & Radiographic film(mm) & $\begin{array}{c}\text { Ionization } \\
\text { chamber(mm) }\end{array}$ \\
\hline $10 \times 10$ & 3.5 & 3.2 \\
\hline $12 \times 12$ & 3.7 & 3.4 \\
$15 \times 15$ & 4 & 3.7 \\
$18 \times 18$ & 4.05 & 3.75 \\
$20 \times 20$ & 4.1 & 3.8 \\
\hline $22 \times 22$ & 4.18 & 3.88 \\
$25 \times 25$ & 4.2 & 3.9 \\
$27 \times 27$ & 4.3 & 4 \\
\hline $30 \times 30$ & 4.4 & 4.1 \\
\hline
\end{tabular}

Table 6 Relation between penumbra width and field size for electron beam and 15 mv energy.

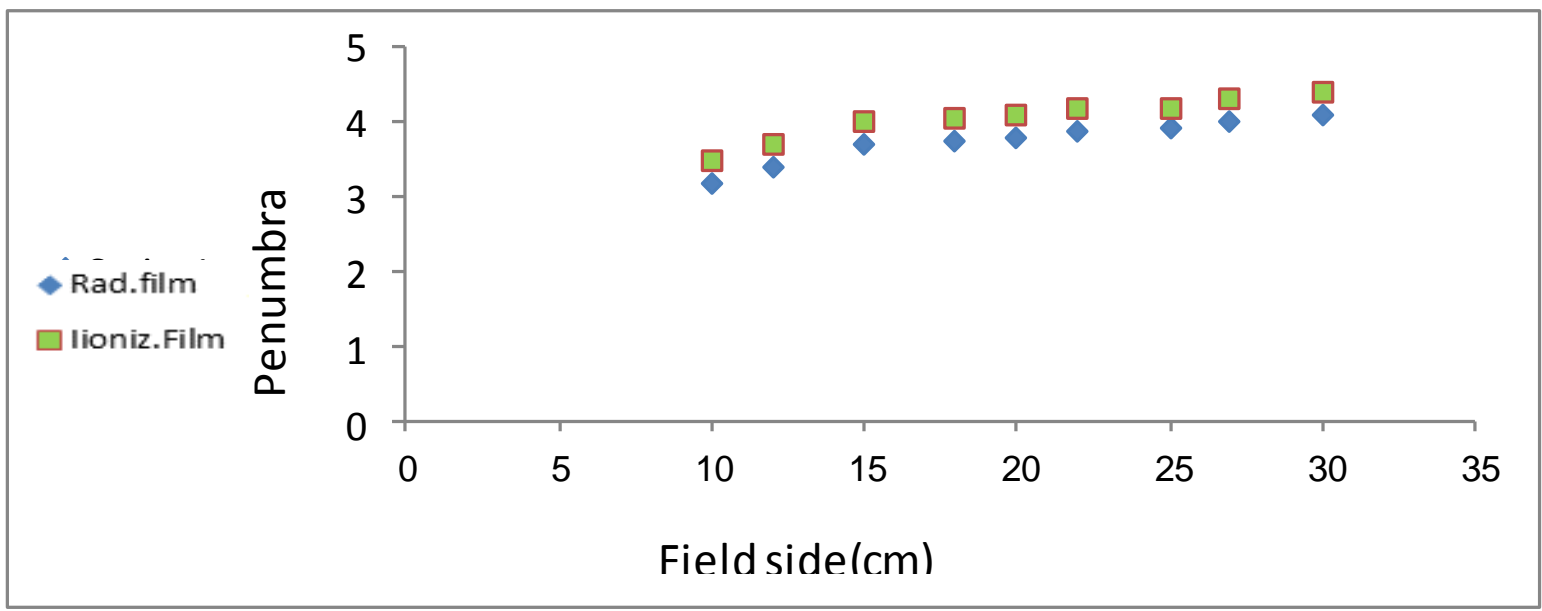

Figure 5 Relation between penumbra width and field size for electron beam and 15 mv energy.

Comparison between radiographic film and ionization chambers is presented in table 6 and figure 5; we noticed that penumbra increase with increasing square field size and the penumbras measured by films larger than that measured by ionization chamber by average $0.3 \mathrm{~mm}$. 


\begin{tabular}{|c|c|c|}
\hline Field size $\left(\mathrm{cm}^{2}\right)$ & $\begin{array}{l}\text { Radiographic } \\
\text { films(mm) }\end{array}$ & $\begin{array}{l}\text { lonization } \\
\text { chamber(mm) }\end{array}$ \\
\hline $0.4 \times 0.4$ & 1.2 & 1.1 \\
\hline $0.6 \times 0.6$ & 1.3 & 1.2 \\
\hline $0.8 \times 0.8$ & 1.5 & 1.4 \\
\hline $1 \times 1$ & 1.6 & 1.5 \\
\hline $1.2 \times 1.2$ & 1.64 & 1.54 \\
\hline $1.4 \times 1.4$ & 1.7 & 1.6 \\
\hline $1.6 \times 1.6$ & 1.7 & 1.6 \\
\hline $1.8 \times 1.8$ & 1.76 & 1.66 \\
\hline $2 \times 2$ & 1.78 & 1.68 \\
\hline $2.2 \times 2.2$ & 1.8 & 1.7 \\
\hline $2.4 \times 2.4$ & 1.82 & 1.72 \\
\hline $2.6 \times 2.6$ & 1.94 & 1.74 \\
\hline $2.8 \times 2.8$ & 1.98 & 1.78 \\
\hline $3 \times 3$ & 1.99 & 1.79 \\
\hline $3.2 \times 3.2$ & 2 & 1.8 \\
\hline $3.4 \times 3.4$ & 2.02 & 1.82 \\
\hline $3.6 \times 3.6$ & 2.1 & 1.9 \\
\hline $3.8 \times 3.8$ & 2.13 & 1.93 \\
\hline $4 \times 4$ & 2.3 & 2.1 \\
\hline $4.2 \times 4.2$ & 2.33 & 2.13 \\
\hline $4.5 \times 4.5$ & 2.4 & 2.2 \\
\hline
\end{tabular}

Table 7 penumbra Measurement for very small field size 6 mv photon beam.

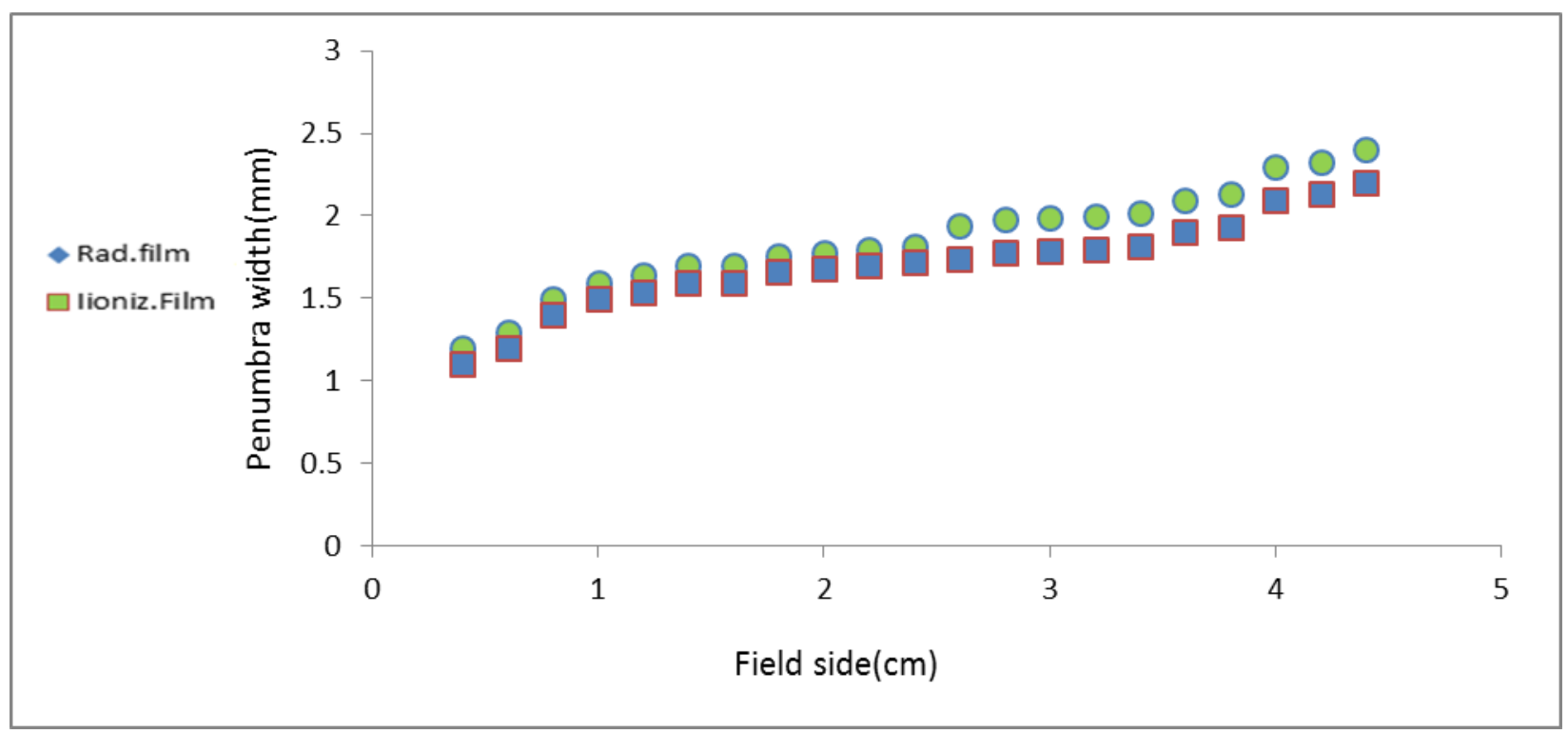

Figure 6 penumbras Measurement for very small field size 6 mv photon beams.

Table 7 and figure 6 present data obtained by using collimator with small leaf dimension to produce very small beams size used in brain tumors. The leaf-end penumbra width for SSD $100 \mathrm{~cm}$.the maximum difference between penumbra 


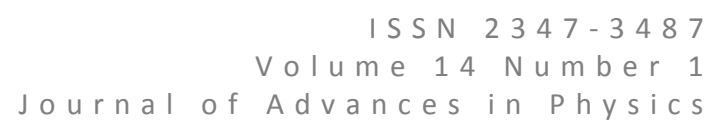

region measured by ionization chamber and that measured by radiographic films is $0.2 \mathrm{~mm}$ which considered as very small difference.

\section{Conclusion}

Penumbra is an important physical parameter in beam modeling which used in predicting dose distribution for step and shoot and dynamic radiotherapy.

In this work two tools of measuring penumbra were used which they are Kodak X-Omat $V$ and simplex ionization chamber.

For $6 \mathrm{Mev}$ photon beam results show that average $80-20 \%$ beam penumbra was found to be $3.9 \mathrm{~mm}$ and $3.6 \mathrm{~mm}$ for radiographic films and ionization chamber respectively. The average difference is measured and found to be $0.3 \mathrm{~mm}$.

By using square field sizes ranging from $10 \times 10 \mathrm{~cm}^{2}$ to $30 \times 30 \mathrm{~cm}^{2}$ penumbra increased with increasing field side.

For $15 \mathrm{Mev}$ photon beam the average penumbra were found to be $3.2 \mathrm{~mm}$ and $2.8 \mathrm{~mm}$ for radiographic films and ionization chamber respectively. The average difference is measured and found to be $0.4 \mathrm{~mm}$.

For $6 \mathrm{Mv}$ electrons beam the average penumbra were found to be $4.7 \mathrm{~mm}$ and $4.4 \mathrm{~mm}$ for radiographic films and ionization chamber respectively. The average difference is measured and found to be $0.3 \mathrm{~mm}$

For $15 \mathrm{Mv}$ electrons beam the average penumbra were found to be $4 \mathrm{~mm}$ and $3.7 \mathrm{~mm}$ for radiographic films and ionization chamber respectively. The average difference is measured and found to be $0.3 \mathrm{~mm}$.

For small fields used in stereotactic radiosurgery the average penumbra were found to be $1.8 \mathrm{~mm}$ and1. $7 \mathrm{~mm}$ for radiographic films and ionization chamber respectively. The maximum difference is measured and found to be $0.2 \mathrm{~mm}$

On the basis of all pervious results it is obvious that the difference is less than $1 \mathrm{~mm}$ which considered as small insignificant difference and can be negligible however oxmat $\vee$ Kodak films provide fast ,easy and economic method for penumbra measurement used in radiotherapy dosimetery.

\section{References}

1. S.A. Bhide, C.M. Nutting, "Recent advances in radiotherapy," BMC Med. 8, 25 (2010).

2. J.M. Moran, M. Dempsey A. Eisbruch, "Safety considerations for IMRT: executive summary," Med Phys. 38, 5067-5072 (2011).

3. B.S.Chera, M.Jackson, L.M. Mazur, "Improving quality of patient care by improving daily practice in radiation oncology," Semin Radiat Oncol. 22, 77-85(2012).

4. T.S. Stelljes, A .Harmeyer, J. Reuter I. , " Dosimetric characteristics of the novel 2D ionization chamber array OCTAVIUS Detector,” Med Phys. 42, 1528-1537.(2015)

5. C. Elith, S. E. Dempsey, N. Findlay, " An introduction to the intensity-modulated radiation therapy (IMRT) techniques, tomotherapy and VMAT," J Med Imag Rad Sci. 42, 37-43(2011).

6. A.S. Garden, W.H. Morrison, D.I. Rosenthal, K.S. Chao, K.K. Ang , "Target coverage for head and neck cancers treated with IMRT," Semin Radiat Oncol. 14, 103-109 (2004).

7. T. Bortfeld, "IMRT: a review and preview," Phys Med Biol. 51, R363-R379 (2006).

8. T. J. Wang, N. Riaz, S.K. Cheng, J. J. Lu, N.Y., "Lee Intensity-modulated radiation therapy for nasopharyngeal carcinoma," J Radiat Oncol. 1, 129-146 (2012).

9. C. B. Saw, K. M. Ayyangar, W. Zhen, R. B. Thompson, and C. A. Enke,"Commissioning and quality assurance for MLC-based IMRT," Med. Dosim 26, 125-133 (2000).

10. T. LoSasso, C. S. Chui, and C. C. Ling, "Comprehensive quality assurance for the delivery of intensity modulated radiotherapy with a multileaf collimator used in the dynamic mode," Med. Phys. 28, 2209-2219 (2001).

11. D.Low, J. Moran, J.F.Dempsey, L. Dong, and M. Oldham, "Dosimetery Tools and Techniques for IMRT," Medical Physics, 38, 1313-1338. (2011)

12. H.Hrsak, M. Major, T. Grego, J. Bibic, and Z. Heinrich, "Correction of Measured Gamma-Knife Output Factors for Angular Dependence of Diode Detectores and PinPiont Ionization Chamber," Physica Medica, 30, 914919.(2014).

13. T. Rachi, Y. Iwamoto, M. Tamura, K. Ota, T. Shimosato, Y. Obata, and M. Komori, "Study of Collimator Scatter Factor (Sc) and Phantom Scatter Factor (Sp) Using Monte Carlo Simulation," Proceeding of the 19th EGS Users' Meeting in Japan, KEK Proc 2012-7, 76. (2012)

14. S. J. Shepard, J. Wang, M. Flynn, E. Gingold, L. Goldman, K. Krugh, D. L.Leong, E. Mah, K. Ogden, D. Peck, E. Samei, J. Wang, and C. E. Willis, "An exposure indicator for digital radiography: AAPM Task Group 116(executive summary)," Med. Phys.36, 2898-2914 (2009). 
15. International Electro technical Commission, Medical electrical equipment-Exposure index of digital x-ray imaging systems-Part1: Definitions and requirements for general radiography, IEC 62494-1, International Electro technical Commission ed. 1.0, Geneva, 2008.

\section{Author' biography}

Dr.Ehab abdel Rahim Hegazy

Working as lectuer of medical physics

,faculty of pharmacy, Delta university for

science and technology .

Egypt.

ehabhegazy99@yahoo.com 